\title{
Clinical Variant
}

National Cancer Institute

\section{Source}

National Cancer Institute. Clinical Variant. NCI Thesaurus. Code C106134.

A form of a disease with clinical features that differ from other forms of the same disease. 